\title{
Nonlinear Dynamics Traction Battery Modeling
}

\author{
Antoni Szumanowski \\ Warsaw University of Technology, \\ Poland
}

\section{Introduction}

This chapter presents a method of determining electromotive force (EMF) and battery internal resistance as time functions, which are depicted as functions of state of charge (SOC). The model is based on battery discharge and charge characteristics under different constant currents that are tested by a laboratory experiment.

Further the method of determining the battery SOC according to the battery modeling result is considered. The influence of temperature on battery performance is analyzed according to laboratory-tested data and the theoretical background for calculating the SOC is obtained. The algorithm of battery SOC indication is depicted in detail. The algorithm of battery SOC "online" indication considering the influence of temperature can be easily used in practice by microprocessor. NiMH and Li-ion battery are taken under analyze. In fact, the method also can be used for different types of contemporary batteries, if the required test data are available.

Hybrid electric (HEVs) and electric (EVs) vehicles are remarkable solutions for the world wide environmental and energy problem caused by automobiles. The research and development of various technologies in HEVs is being actively conducted [1]-[8]. The role of battery as power source in HEVs is significant. Dynamic nonlinear modeling and simulations are the only tools for the optimal adjustment of battery parameters according to analyzed driving cycles. The battery's capacity, voltage and mass should be minimized, considering its over-load currents. This is the way to obtain the minimum cost of battery according to the demands of its performance, robustness, and operating time.

The process of battery adjustment and its management is crucial during hybrid and electric drives design. The generic model of electrochemical accumulator, which can be used in every type of battery, is carried out. This model is based on physical and mathematical modeling of the fundamental electrical impacts during energy conservation by a battery. The model is oriented to the calculation of the parameters EMF and internal resistance. It is easy to find direct relations between SOC and these two parameters. If the EMF is defined and the function versus the $\operatorname{SOC}(k \in<0,1>)$ is known, it is simple to depict the discharge/charge state of a battery.

The model is really nonlinear because the correlative parameters of equations are functions of time [or functions of SOC because $S O C=f(t)$ ] during battery operation. The modeling method presented in this chapter must use the laboratory data (for instance voltage for different constant currents or internal resistance versus the battery SOC) that are expressed

Source: Nonlinear Dynamics, Book edited by: Todd Evans,

ISBN 978-953-7619-61-9, pp. 366, January 2010, INTECH, Croatia, downloaded from SCIYO.COM 
in a static form. These data have to be obtained discharging and charging tests. The considered generic model is easily adapted to different types of battery data and is expressed in a dynamic way using approximation and iteration methods.

An HEV operation puts unique demands on battery when it operates as the auxiliary power source. To optimize its operating life, the battery must spend minimal time in overcharge and or overdischarge. The battery must be capable of furnishing or absorbing large currents almost instantaneously while operating from a partial-state-of-charge baseline of roughly $50 \%$ [9]. For this reason, knowledge about battery internal loss (efficiency) is significant, which influences the battery SOC.

There are many studies dedicated to determine the battery SOC [10]-[22]; however, these solutions have some limitations for practical application [23]. Some solutions for practical application are based on a loaded terminal voltage [17]-[20] or a simple calculation the flow of charge to/from a battery [21]-[22], which is the integral that is based on current and time. Both solutions are not considered the strong nonlinear behavior of a battery. It is possible to determine transitory value of the SOC "online" in real drive conditions with proper accuracy, considering the nonlinear characteristic of a battery by resolving the mathematical model that is presented in this paper.

This is the background for optimal battery parameters as well as the proper battery management system (BMS) design - particularly in the case of SOC indication [25]. The high power (HP) NiMH and LiIon batteries so common used in HEV were considered.

Finally, for instance, the plots of battery voltage, current and SOC as alterations in time for real experimental hybrid drive equipped with BMS especially design according to presented original battery modeling method, are attached.

\section{Battery dynamic modeling}

\subsection{Battery physical model}

The basis enabling the formulation of the energy model of an electrochemical battery is battery physical model shown in Fig.1.

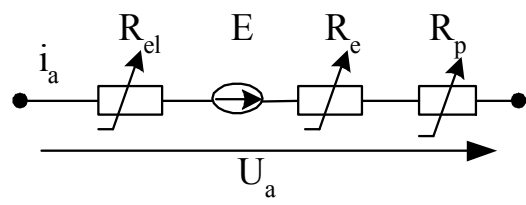

Fig. 1. Substitute circuit for nonlinear battery modeling

\subsection{Mathematical modeling}

The internal resistance can be expressed in an analytical way [7], where:

$$
R_{w}\left(i_{a}, \tau, Q\right)=R_{e l}(\tau, Q)+R_{e}(Q)+b E\left(i_{a}, \tau, Q\right) I_{a}^{-1}
$$

$b E\left(i_{a}, \tau, Q\right) I_{a}^{-1}$ is the resistance of polarization.

$b$ is the coefficient that expresses the relative change of the polarization's EMF on the cell's terminals during the flow of the $I_{a}$ current in relation to the EMF E for nominal capacity. Electrolyte resistance $R_{e l}$ and electrode resistance $R_{e}$ are inversely proportional to 
temporary capacity of the battery. During real operation, the capacity of the battery is changeable with respect to current and temperature [7], i.e.,

$$
Q_{u}\left(i_{a}, t, \tau\right)=Q_{\tau}(\tau)-K_{w}\left(i_{a}(t), t\right)
$$

or

$$
Q_{u}\left(i_{a}, t, \tau\right)=Q_{\tau}\left(\tau, i_{a}\right)-\int_{0}^{t} i_{a}(t) \mathrm{d} t
$$

Where:

$K_{w}\left(i_{a}(t), t\right)$ is the nonlinear function that is used to calculate the battery discharged capacity $\int_{0}^{t} i_{a}(t) \mathrm{d} t$ is the function that is used to calculate the used charge, which has been drawn from the battery since the instant time $\mathrm{t}=0$ till the time $\mathrm{t}$

$Q_{\tau}\left(\tau, i_{a}\right)$ is the battery capacity as a function of temperature and load current, and

$$
K_{w}=i_{a}^{n(\tau)} t
$$

where $K_{w}$ is the discharge capacity of the battery, $\mathrm{n}$ is the Peukert's constant, which varies for different types of batteries.

Assuming temperature influence:

$$
Q_{u}(i, t, \tau)=c_{\tau}(\tau) Q_{\tau n}\left(\frac{i_{a}(t)}{I_{n}}\right)^{-\beta}-\int_{0}^{t} i_{a}(t) \mathrm{d} t
$$

where the $c_{\tau}(\tau)$ coefficient can be defined as the temperature index of nominal capacity [7], i.e.,

$$
c_{\tau}(\tau)=\frac{Q_{\tau}}{Q_{\tau n}}=\frac{1}{1+\alpha\left|\left(\tau_{n}-\tau\right)\right|}
$$

where $\alpha$ is the temperature capacity index (we can assume $\alpha \approx 0.01 \mathrm{deg}^{-1}$ ).

According to the Peukert equation, we can get the following:

$$
\frac{Q\left(i_{a}\right) \bar{U}}{Q_{\tau n} \bar{U}}=\left(\frac{i_{a}(t)}{I_{n}}\right)^{-\beta(\tau)}
$$

The left -hand side of the equation (7) is the quotient of the electric power that is drawn from the battery during the flow of $i_{a} \neq I_{n}$ current and the electric power that is drawn from the battery during loading with the rated current. The quotient mentioned above defines the usability index of the accumulated power, i.e.,

$$
\eta_{A}\left(i_{a}, \tau\right)=\left(\frac{i_{a}(t)}{I_{n}}\right)^{-\beta(\tau)}
$$


When $i_{a}<I_{n}$, the value of the index can exceed 1 .

During further solution of (5), it can be transformed by means of (8), i.e.,

$$
Q_{u}(i, t, \tau)=c_{\tau}(\tau) \eta_{A}\left(i_{a}, \tau\right) Q_{\tau n}-\int_{0}^{t} i_{a}(t) \mathrm{d} t
$$

Therefore, the real battery SOC can be expressed in the following way [7]:

$$
k=\frac{Q_{u}}{Q_{\tau n}}=\frac{c_{\tau}(\tau) \eta_{A}\left(i_{a}, \tau\right) Q_{\tau n}-\int_{0}^{t} i_{a}(t) \mathrm{d} t}{Q_{\tau n}}
$$

where $k=1$ for a nominally charged battery, $0 \leq k \leq 1$, and thus

$$
k=c_{\tau}(\tau) \eta_{A}\left(i_{a}, \tau\right)-\frac{1}{Q_{\tau n}} \int_{0}^{t} i_{a}(t) \mathrm{d} t
$$

For practical application, it's necessary to transform aforementioned equations for determining the internal resistance $R_{w}$ and $E M F$ as functions of $k$ (SOC) [7], i.e.,

$$
\begin{gathered}
R_{w}\left(i_{a}, \tau, Q\right)=\frac{l_{1}}{Q_{u}\left(i_{a}, t, \tau\right)}+\frac{l_{2}}{Q_{u}\left(i_{a}, t, \tau\right)}+\frac{b E\left(i_{a}, \tau, Q\right)}{i_{a}(t)} \\
R_{w}\left(i_{a}, t, \tau\right)=l k^{-1}+b \frac{E(k)}{i_{a}(t)}
\end{gathered}
$$

where $l=\left(l_{1}+l_{2}\right) Q_{\tau n}{ }^{-1}, l \approx$ const is a piecewise constant, assuming that the temporary change of the battery capacity is significantly smaller than its nominal capacity; the coefficient 1 is experimentally determined under static conditions. $E(k)$ is the temporary value of polarization's EMF, which is dependent on the SOC.

The EMF as a function of $k$ is deduced from the well-know battery voltage equation, including the momentary value of voltage and internal resistance, because the values $R_{w}$ and EMF are unknown. The solution can be obtained by a linearization and iterative method, which is explained by following Fig.2 and following:

$$
b(k)=\frac{E(k)-E_{\min }^{*}}{E_{\max }^{*}}
$$

Take under consideration (12)-(14), it's then possible to obtain the following:

$$
\left\{\begin{array}{l}
R_{w}\left(k_{n}\right)=\frac{E\left(k_{n}\right)-E_{\min }^{*}}{E_{\max }^{*}} \frac{E\left(k_{n}\right)}{I_{n}}+\frac{l\left(k_{n}\right)}{k_{n}} \\
R_{w}\left(k_{n-1}\right)=\frac{E\left(k_{n-1}\right)-E_{\min }^{*}}{E_{\max }^{*}} \frac{E\left(k_{n-1}\right)}{I_{n}}+\frac{l\left(k_{n-1}\right)}{k_{n-1}}
\end{array}\right.
$$

Obviously, $E(k)$ is the function that we need. To obtain it, it's necessary to use the known functions $u_{a}(k)$, which are obtained by laboratory tests. 


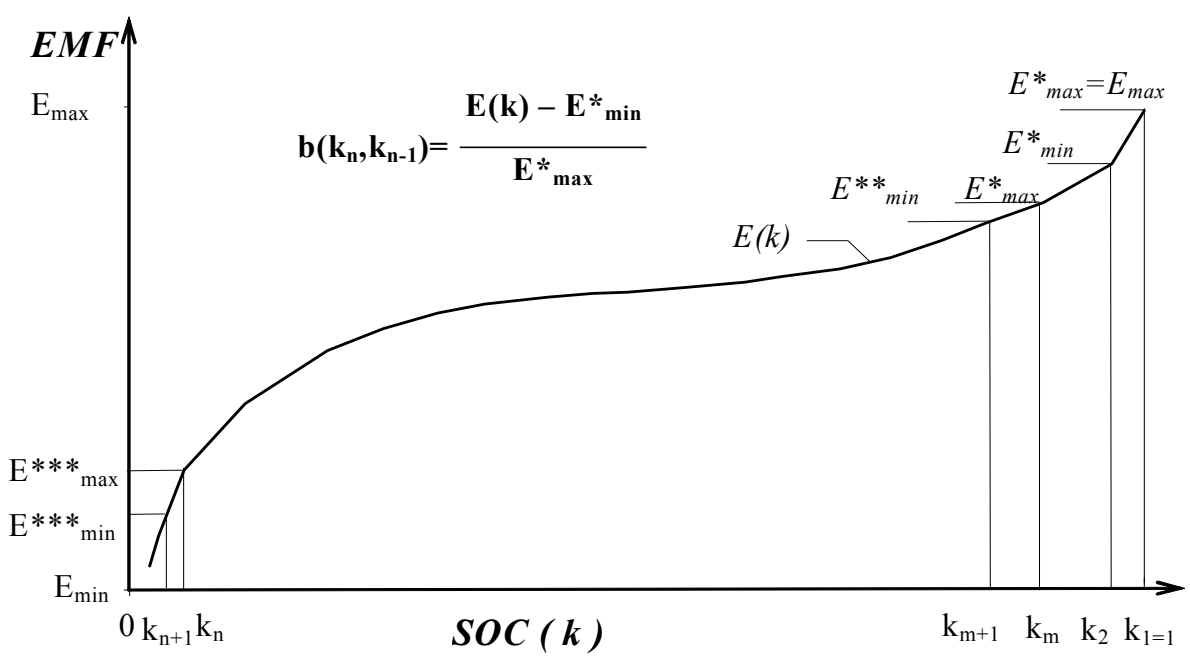

Fig. 2. Linearization method of EMF versus SOC (k)

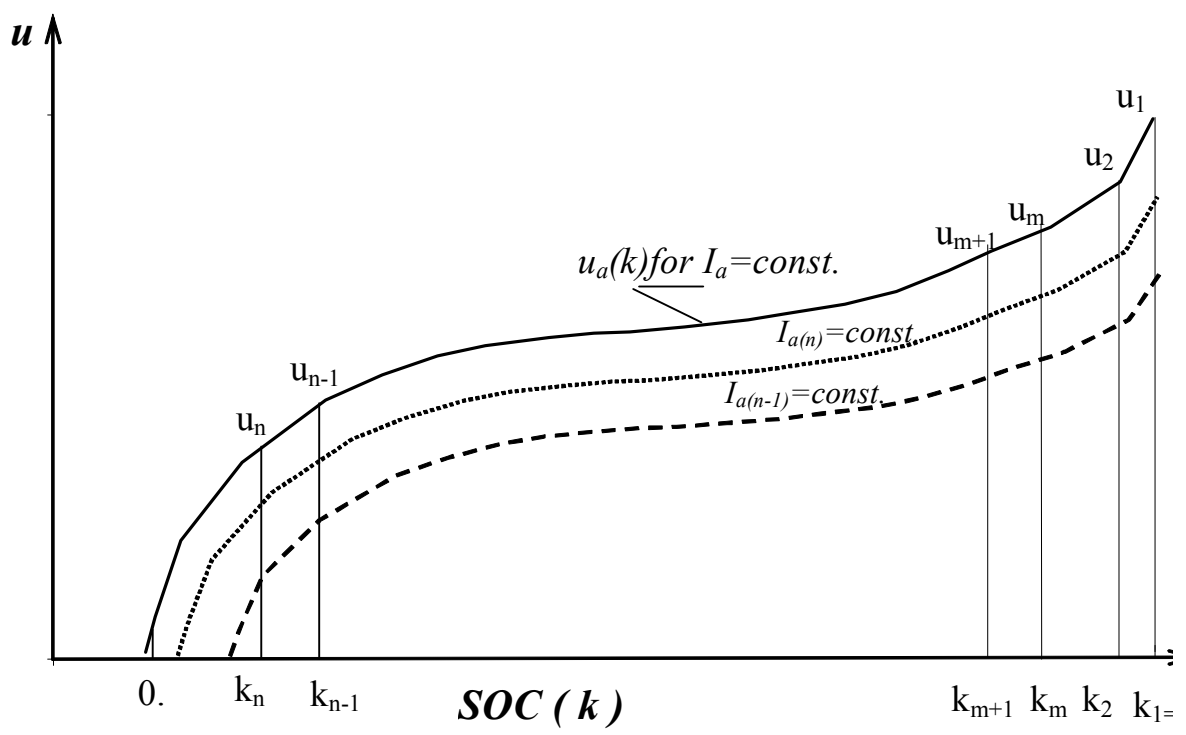

Fig. 3. Linearization method of voltage versus SOC (k)

Similarly as in the case of Fig.3, the following equations are generated:

$$
\left\{\begin{array}{l}
u\left(k_{n}\right)=E\left(k_{n}\right) \pm I_{a} R_{w}\left(k_{n}\right) \\
u\left(k_{n-1}\right)=E\left(k_{n-1}\right) \pm I_{a} R_{w}\left(k_{n-1}\right)
\end{array}\right.
$$

$u\left(k_{n}\right)$ and $u\left(k_{n-1}\right)$ are known from the family of voltage characteristics that are obtained by laboratory tests. $I_{a(n)}$ is also known because $u\left(k_{n}\right)$ is determined for $I_{a(n)}=$ const. 


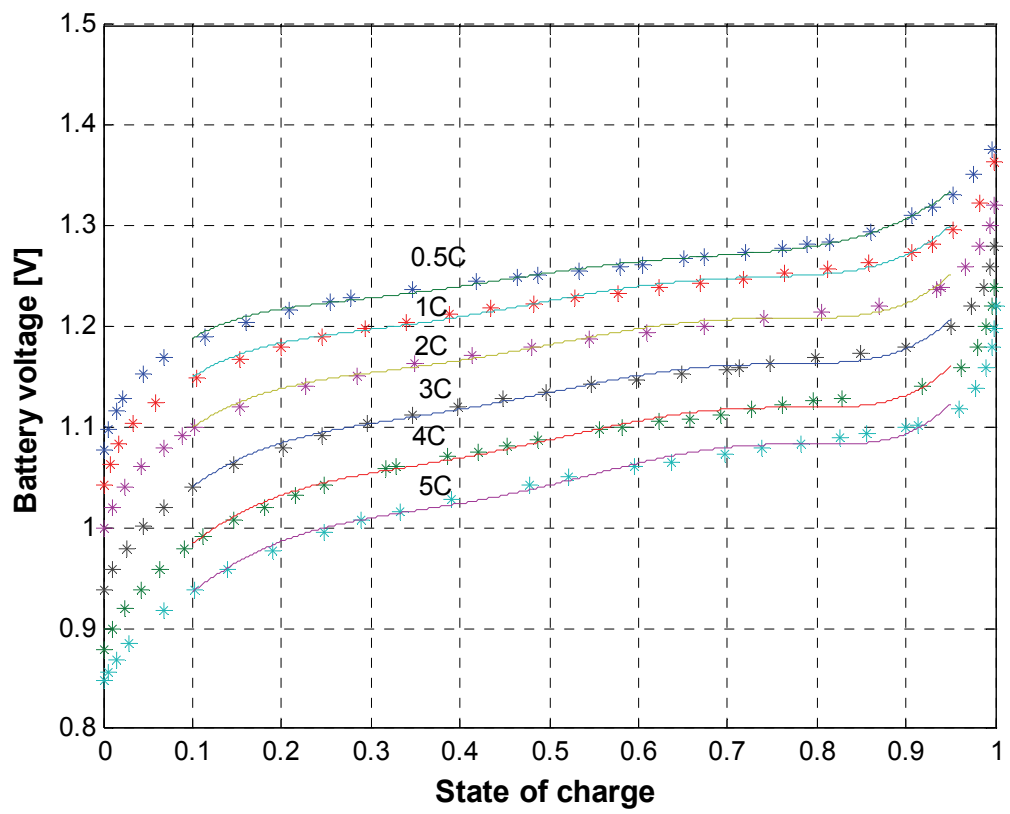

Fig. 4. Discharging data of a 14-Ah NiMH battery

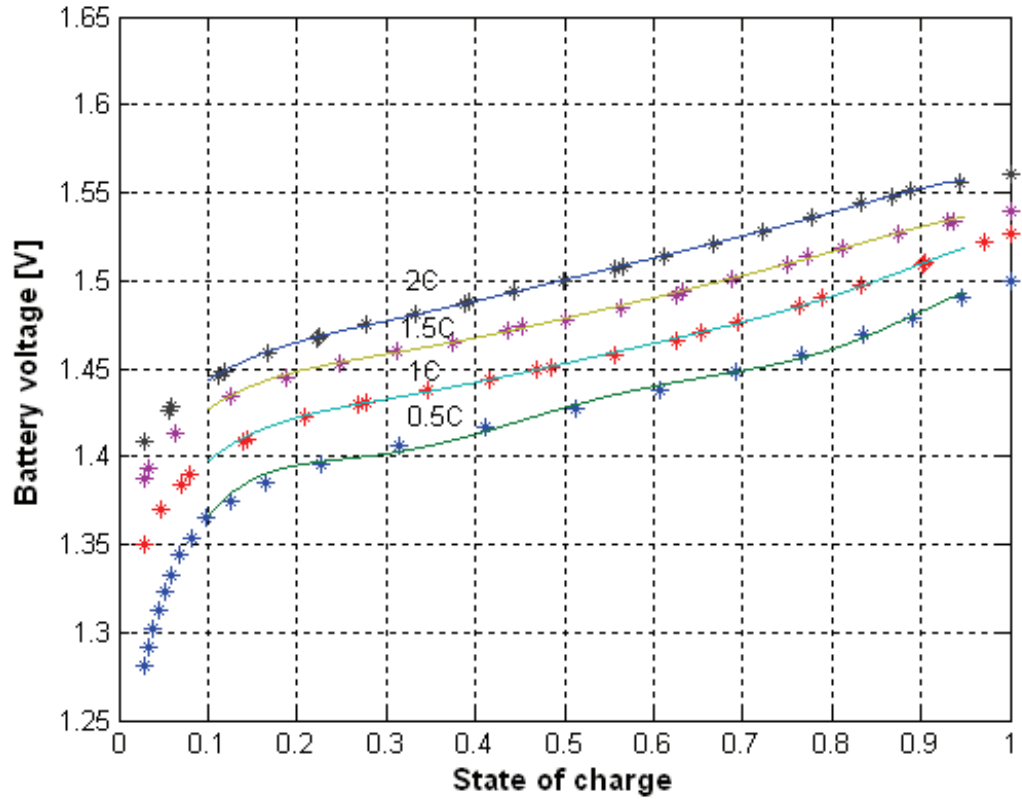

Fig. 5. Charging data of a 14-Ah NiMH battery 
+ is for discharge

- is for charge

$k \in<0,1>$

Using the above-presented approach, based on experimental data (shown in Figs.4 and 5), it's possible to construct a proper equation set as in the shape of (15) and (16) and resolve it in an iterative way.

Last, the equations of $R_{w}$ and $E M F$ take the shape of the following polynomial:

$$
\begin{aligned}
& R_{w}(k)=A_{r} k^{6}+B_{r} k^{5}+C_{r} k^{4}+D_{r} k^{3}+E_{r} k^{2}+F_{r} k+G_{r} \\
& E(k)=A_{e} k^{6}+B_{e} k^{5}+C_{e} k^{4}+D_{e} k^{3}+E_{e} k^{2}+F_{e} k+G_{e} \\
& b(k)=A_{b} k^{6}+B_{b} k^{5}+C_{b} k^{4}+D_{b} k^{3}+E_{b} k^{2}+F_{b} k+G_{b} \\
& l(k)=A_{l} k^{7}+B_{l} k^{6}+C_{l} k^{5}+D_{l} k^{4}+E_{l} k^{3}+F_{l} k^{2}+G_{l} k+H_{l}
\end{aligned}
$$

\section{Battery modeling results}

The basic elements that are used to formulate the mathematical model of a NiMH battery are the described iteration-approximation method and the approximations based on the battery discharging and charging characteristics that are obtained by an experiment. Experimental data are approximated to enable determination of the internal resistance in a small-enough range $\mathrm{k}=0.001$. The modeling results (Figs. 6-8) in the battery SOC operating range of 0.1-0.95 show a small deviation (less than 1\%) from the experimental data (Figs.9 and 10). The NiMH battery that is used in the experiment and the modeling is an HP battery for HEV application. The nominal voltage of the battery is $1.2 \mathrm{~V}$, and the rated capacity 14Ah.

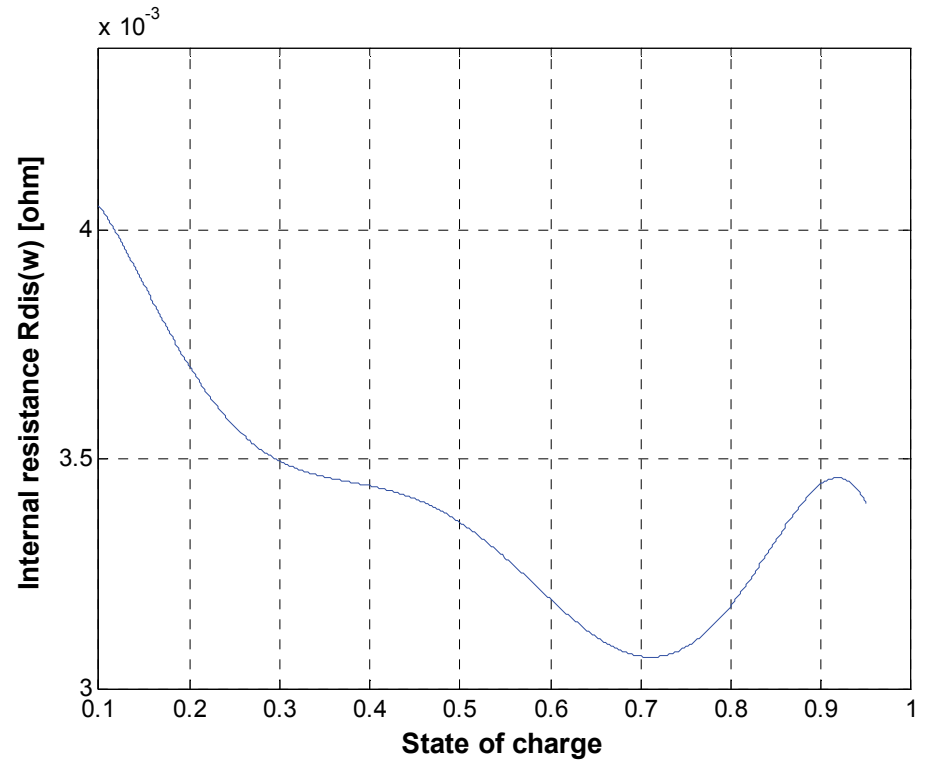

Fig. 6. Computed internal resistance characteristics of a 14-Ah NiMH battery for discharging 


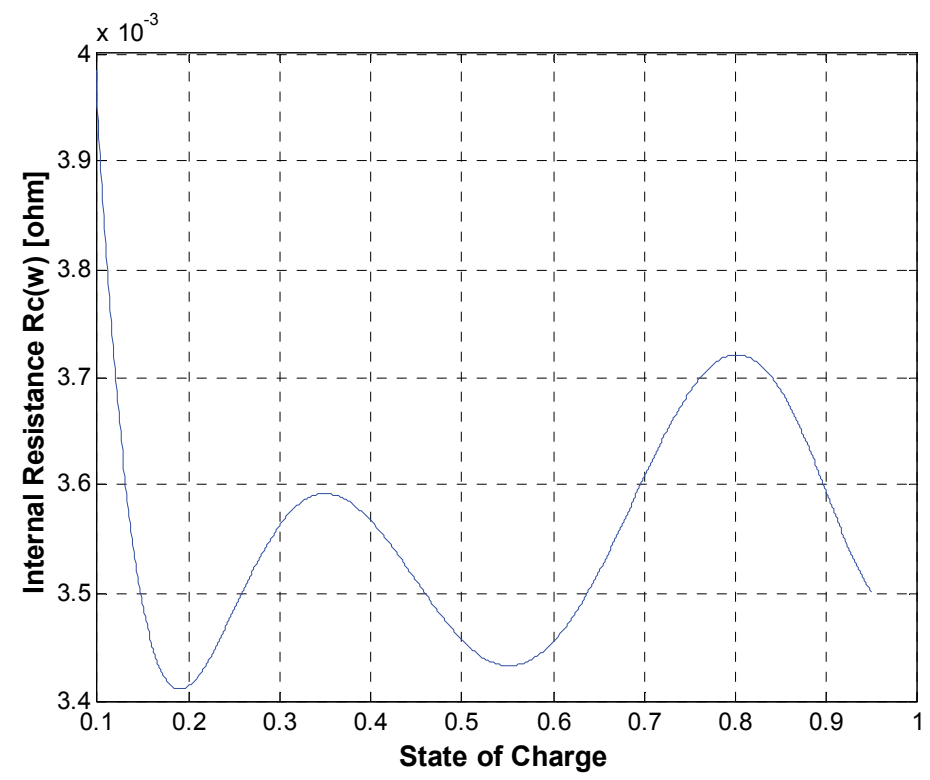

Fig. 7. Computed internal resistance characteristics of a 14-Ah NiMH battery for charging

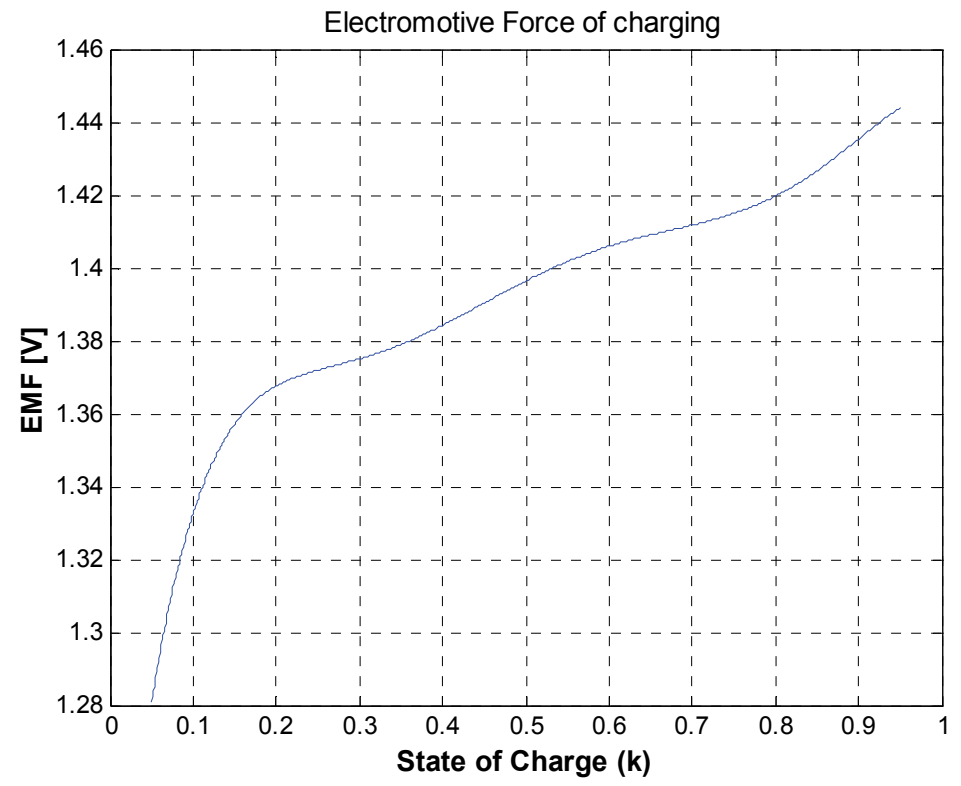

Fig. 8. Computed EMF of a 14-Ah NiMH battery

After approximation according to the computed results, approximated equations of (17) for 14Ah NiMH battery can be obtained. These factors of equations (17) are available in Table 1. 


\begin{tabular}{|c|c|c|c|c|c|}
\hline \multirow{3}{*}{$\begin{array}{c}\text { Factors of } \\
\text { Equation } \\
\text { (17) }\end{array}$} & \multirow{3}{*}{$\begin{array}{c}\text { Internal } \\
\text { resistance } \mathrm{R}(\mathrm{w}) \\
\text { during } \\
\text { discharging }\end{array}$} & \multirow{3}{*}{$\begin{array}{c}\text { Internal } \\
\text { resistance } \\
\mathrm{Rd}(\mathrm{w}) \text { during } \\
\text { charging }\end{array}$} & \multirow{3}{*}{$\begin{array}{l}\text { Electromotive } \\
\text { Force }\end{array}$} & Coefficient b & Coefficient 1 \\
\hline & & & & Discharging & Discharging \\
\hline & & & & Charging & Charging \\
\hline \multirow{2}{*}{$A$} & \multirow{2}{*}{0.65917} & \multirow{2}{*}{0.42073} & \multirow{2}{*}{13.504} & -0.015363 & 0.65917 \\
\hline & & & & 0.015341 & 0.42073 \\
\hline \multirow{2}{*}{$B$} & \multirow{2}{*}{-2.0397} & \multirow{2}{*}{-1.4434} & \multirow{2}{*}{-36.406} & 0.10447 & -2.0528 \\
\hline & & & & -0.10661 & -1.4376 \\
\hline \multirow{2}{*}{ C } & \multirow{2}{*}{2.4684} & \multirow{2}{*}{1.9362} & \multirow{2}{*}{36.881} & -0.18433 & 2.4978 \\
\hline & & & & 0.22702 & 1.9195 \\
\hline \multirow{2}{*}{$D$} & \multirow{2}{*}{-1.4711} & \multirow{2}{*}{-1.2841} & \multirow{2}{*}{-17.198} & 0.13578 & -1.495 \\
\hline & & & & -0.21788 & -1.2661 \\
\hline \multirow{2}{*}{$E$} & \multirow{2}{*}{0.44578} & \multirow{2}{*}{0.43809} & \multirow{2}{*}{3.5264} & -0.045129 & 0.45416 \\
\hline & & & & 0.10346 & 0.42896 \\
\hline \multirow{2}{*}{$F$} & \multirow{2}{*}{-0.065274} & \multirow{2}{*}{-0.071757} & \multirow{2}{*}{-0.10793} & 0.0059814 & -0.066422 \\
\hline & & & & -0.023367 & -0.06961 \\
\hline \multirow{2}{*}{ G } & \multirow{2}{*}{0.0099109} & \multirow{2}{*}{0.0078518} & \multirow{2}{*}{1.234} & $-9.416 e-005$ & 0.0099289 \\
\hline & & & & 0.0020389 & 0.0076585 \\
\hline \multirow{2}{*}{$H$} & & & & & $-1.2154 \mathrm{e}-015$ \\
\hline & & & & & $1.9984 \mathrm{e}-008$ \\
\hline
\end{tabular}

Table 1. Factors of Eq. (17) for 14-Ah NiMH battery

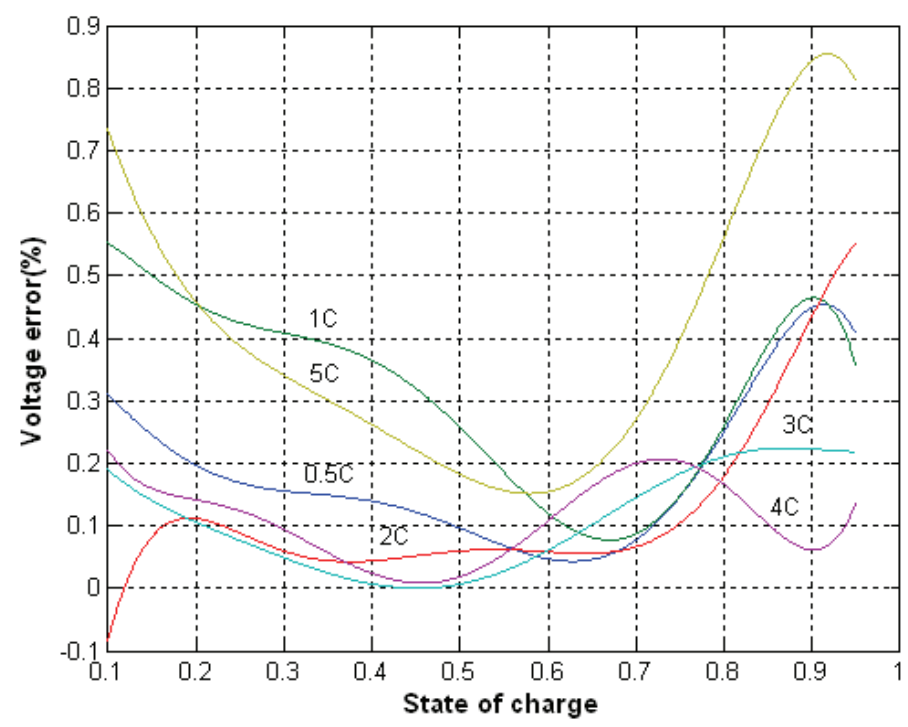

Fig. 9. Error of experiment data and the computed voltage at different discharge currents

The basic element used to formulate the mathematical model of Li-ion battery module from SAFT Company is the earlier described iteration-approximation method and the approximated based on the battery discharging characteristics obtained by experiment. The experimental data is approximated to enable determining the internal resistance in an 
enough small range $k=0.001$. The analyses, in the operating range SOC between $0.01 \sim 0.95$, gives us a small deviation (less than $2 \%$ ) by using the iteration-approximation method from the experimental data. The VL30P-12S module has 30Ah rated capacity and it's special designed for HEV application.

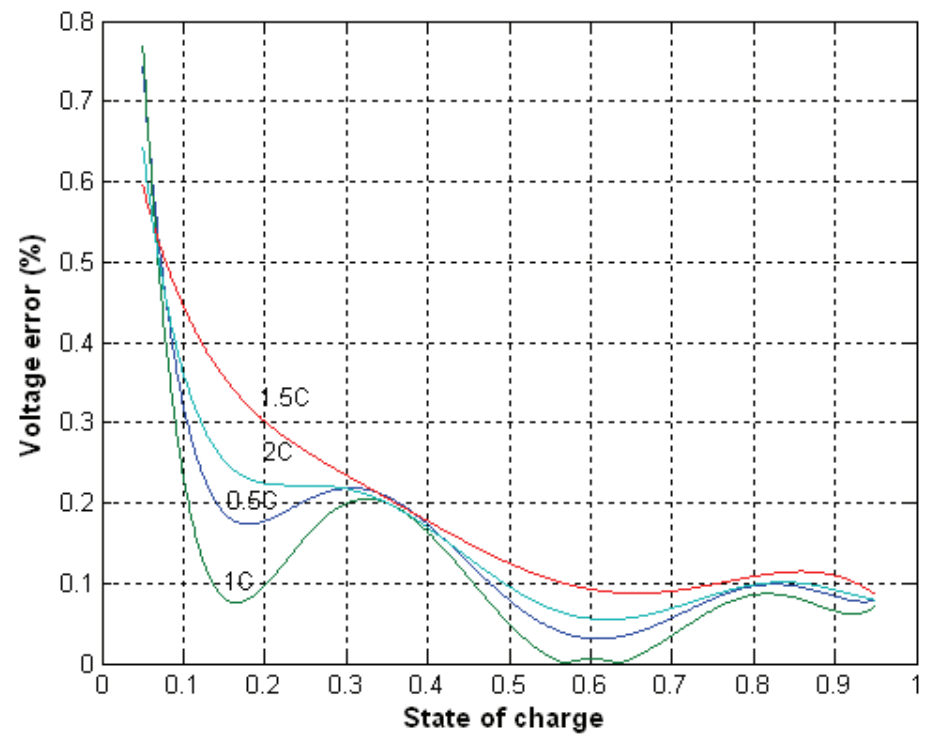

Fig. 10. Error of experiment data and computed voltage at different charge currents

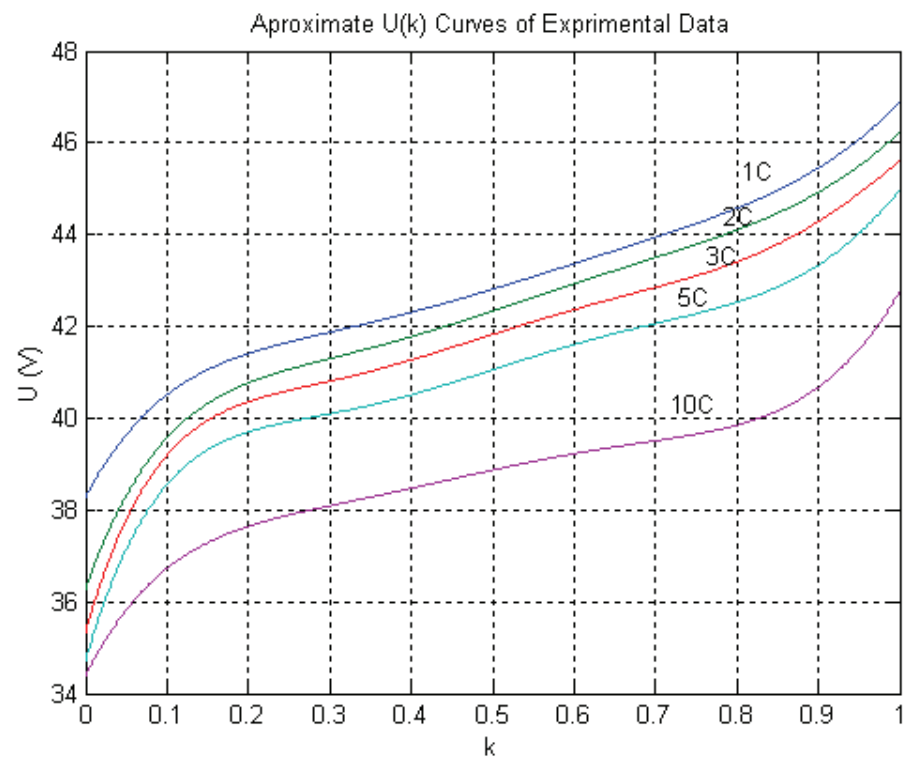

Fig. 11. The discharging voltage characteristics of SAFT 30Ah Li-ion module 


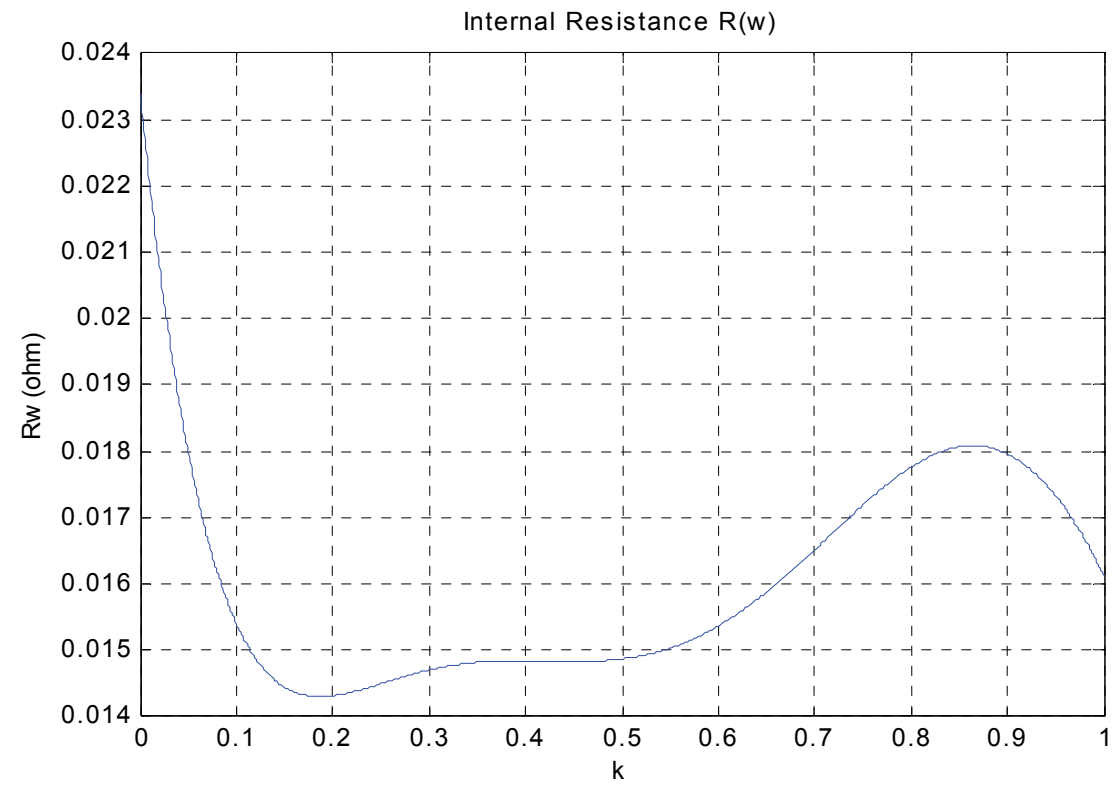

Fig. 12. The computed internal resistance of SAFT 30Ah Li-ion module

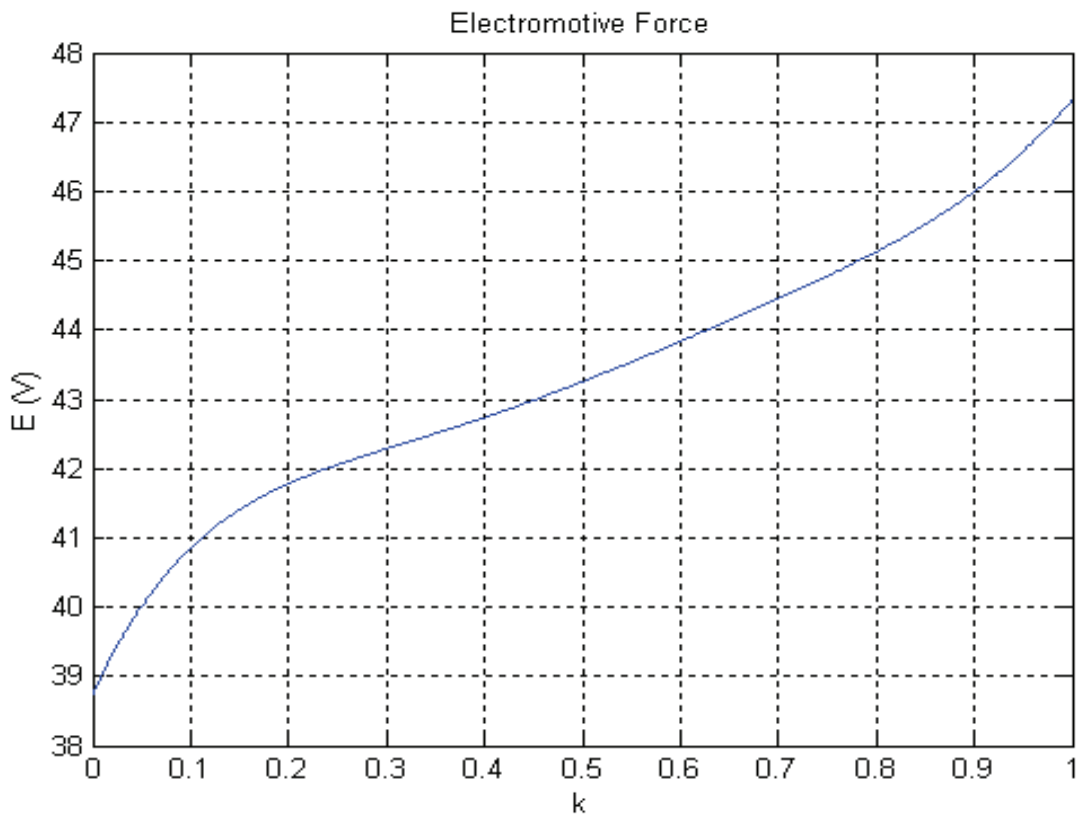

Fig. 13. The computed EMF of SAFT 30Ah Li-ion module 


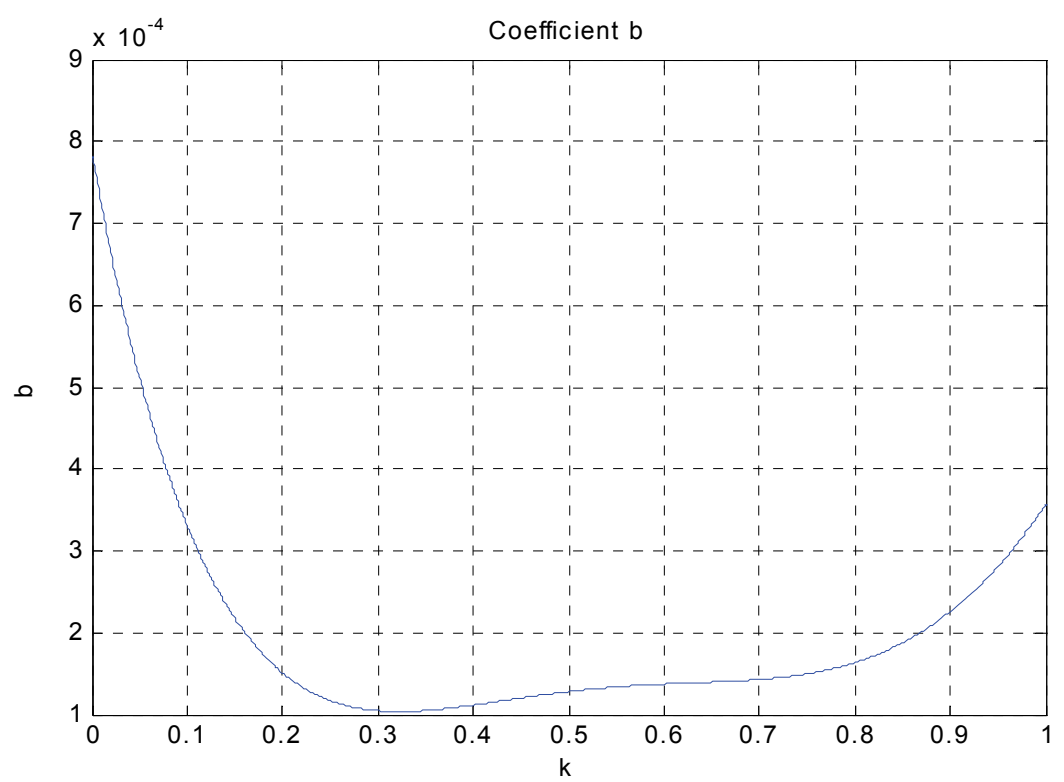

Fig. 14. The computed coefficient b of SAFT 30Ah Li-ion module

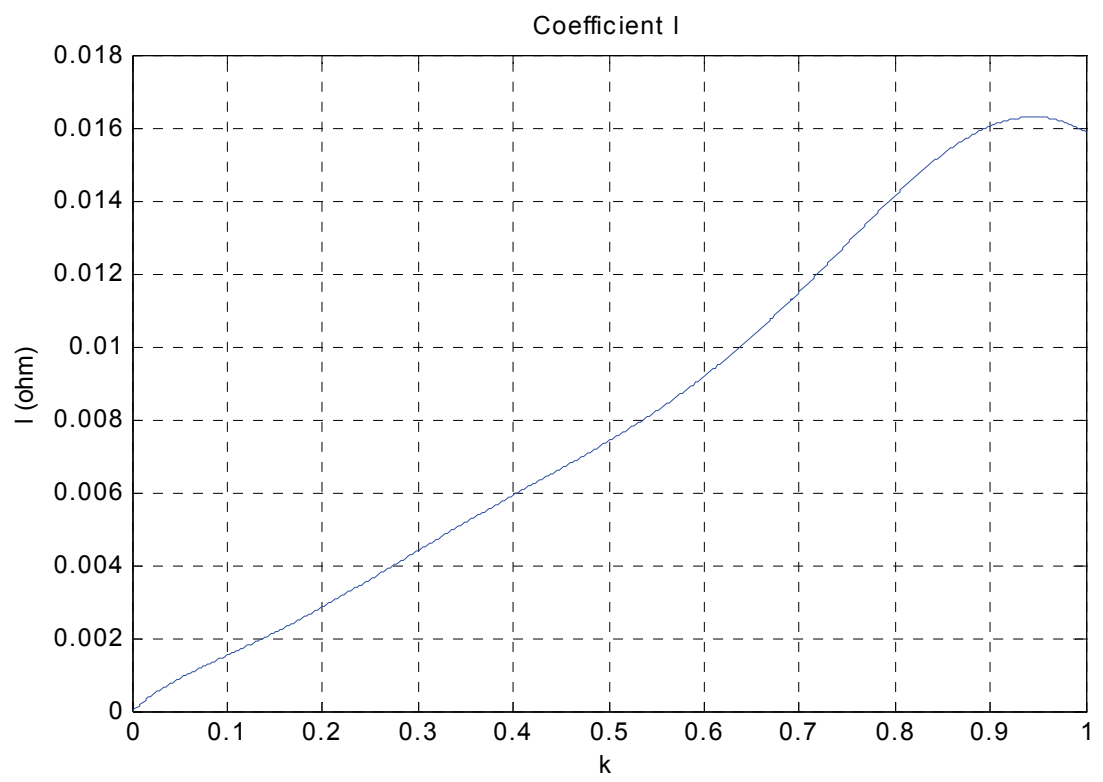

Fig. 15. The computed coefficient 1 of SAFT 30Ah Li-ion module

After approximation according to the computed results, approximated equations of (17) for 30Ah Li-ion module can be obtained. These factors of equations (17) are available in Table 1. 


\begin{tabular}{|c|c|c|c|c|}
\hline $\begin{array}{c}\text { Factors of } \\
\text { equations (6.56) }\end{array}$ & $\begin{array}{c}\text { Internal resistance } \\
\mathrm{R}_{\mathrm{w}}\end{array}$ & $\begin{array}{c}\text { Electromotive force } \\
\mathrm{E}\end{array}$ & Coefficient $\mathrm{b}$ & Coefficient 1 \\
\hline $\boldsymbol{A}$ & 0.71806 & -28.091 & 0.0032193 & 0.71806 \\
\hline $\boldsymbol{B}$ & -2.6569 & 157.05 & -0.016116 & -2.6545 \\
\hline $\boldsymbol{C}$ & 3.7472 & -296.92 & 0.036184 & 3.736 \\
\hline $\boldsymbol{D}$ & -2.5575 & 265.34 & -0.040738 & -2.5406 \\
\hline $\boldsymbol{E}$ & 0.8889 & -119.29 & 0.023539 & 0.87755 \\
\hline $\boldsymbol{F}$ & -0.14693 & 30.476 & -0.0065159 & -0.14352 \\
\hline $\boldsymbol{H}$ & 0.023413 & 38.757 & 0.00078501 & 0.022978 \\
\hline $\boldsymbol{H}$ & & & & $-1.7916 \mathrm{e}-015$ \\
\hline
\end{tabular}

Table 2. Factors of Eq. (17) for 30-Ah Li-ion module

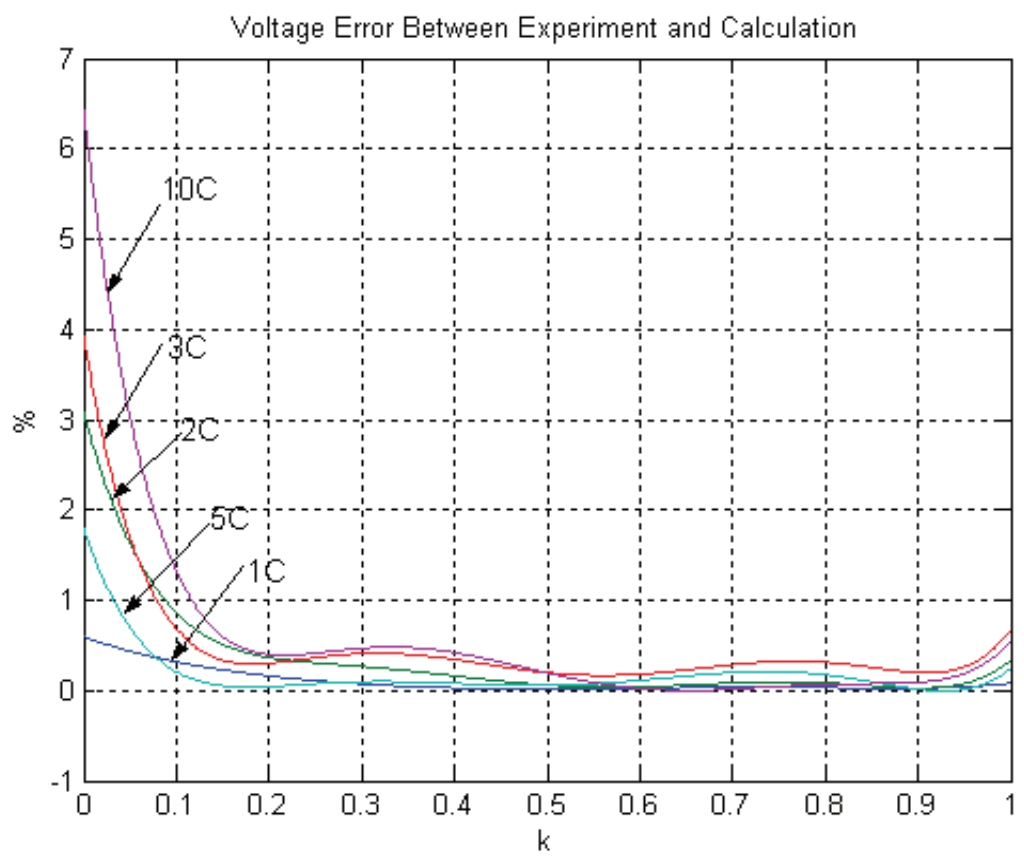

Fig. 16. Errors between testing data and computed result of SAFT 30Ah Li-ion module

\section{Temperature influence analysis on battery performance}

The determination of the battery EMF and internal resistance gives unlimited possibilities of calculating the battery's voltage versus SOC $(\mathrm{k})$ relation for a different value of dischargecharge current. For a real driving condition, the battery discharge or charge depends on the drive architecture influencing the respective power distribution. In majority, battery charging takes place during vehicle regenerative braking, which means that this situation lasts for a relatively short time with a significant peak-current value. A discharging current that is too high results in a rapid increase in the battery temperature. 
The main role of this study is to find a theoretical background for calculating the temperature influence on the battery SOC. The presented method is more accurate and complicated compared with other methods, which doesn't mean that it is more difficult to apply. First of all, it is necessary to make the following assumptions:

The considered battery is fully charged in nominal conditions: nominal current, nominal temperature and nominal capacity $\left(i_{b}=1 \mathrm{C}, \tau_{b}=20^{\circ} \mathrm{C}\right.$, the capacity is designed for nominal parameters, respectively).

The EMF for the considered battery is defined as its nominal condition in the nominal SOC alteration range $k \in<1,0\rangle$. The assumption is taken that the EMF value of $\mathrm{k}=0.15$ is the minimum EMF. For $\mathrm{k}=0$, the EMF is defined as the "minimum-minimorum", in practice which should not be obtained. The same assumption is recommended for a value that is different from the nominal temperature for the $k_{\tau}$ (SOC) definition. As shown in Fig.19, the starting point value of the EMF for a different value from the nominal temperature can be higher or lower, which means that the extension alteration of the SOC could be longer or shorter. For instance (see Fig.17), in the case of the NiMH battery for a value that is higher than the nominal temperature, the discharge capacity is smaller than the nominal, which means that for a certain temperature, the battery capacity corresponding to this temperature is also changed in file $k_{\tau} \in<1,0>$. However, the full $k_{\tau}$ doesn't mean the same discharge capacity as in the case of nominal temperature but does mean the maximum discharge capacity at this temperature. For this reason, in fact, $k_{\tau}$ for this temperature is only $k(t)>k_{\tau}(t)$, [in some case, $k(t)<k_{\tau}(t)$, where $k(t)$ is connected only with nominal conditions].

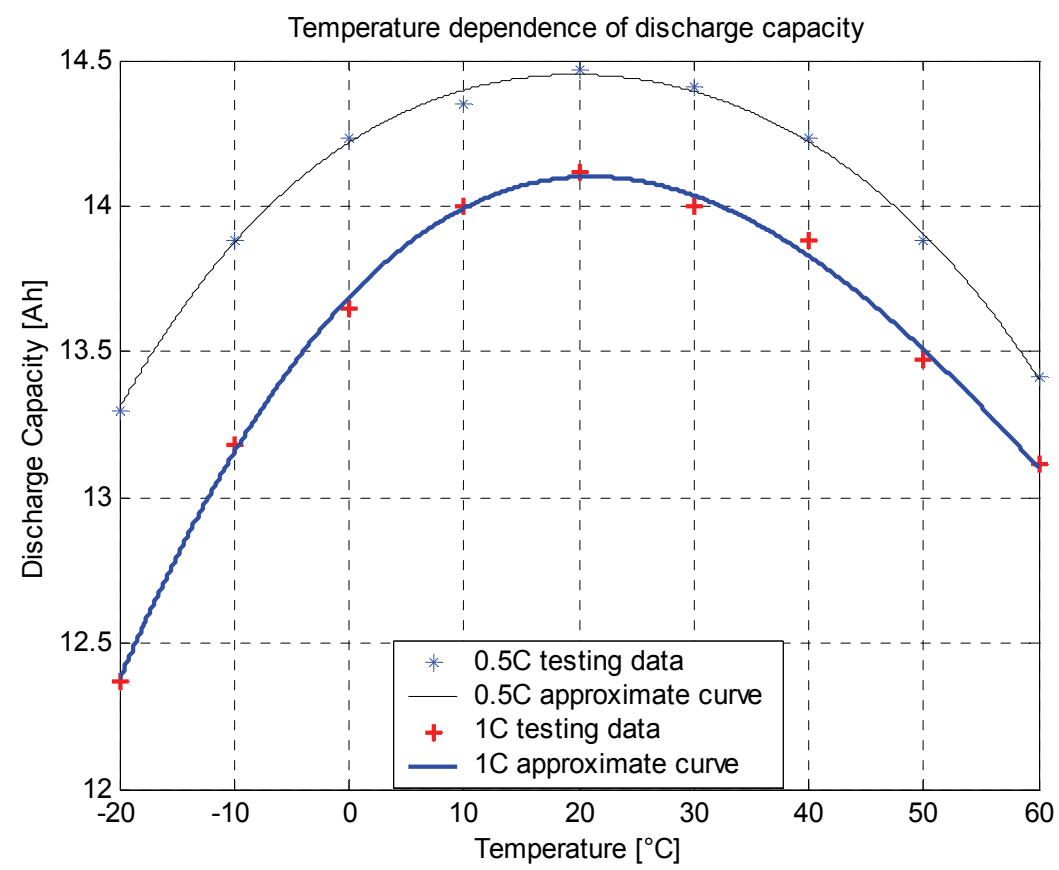

Fig. 17. Temperature dependence of the discharge capacity of the NiMH battery 


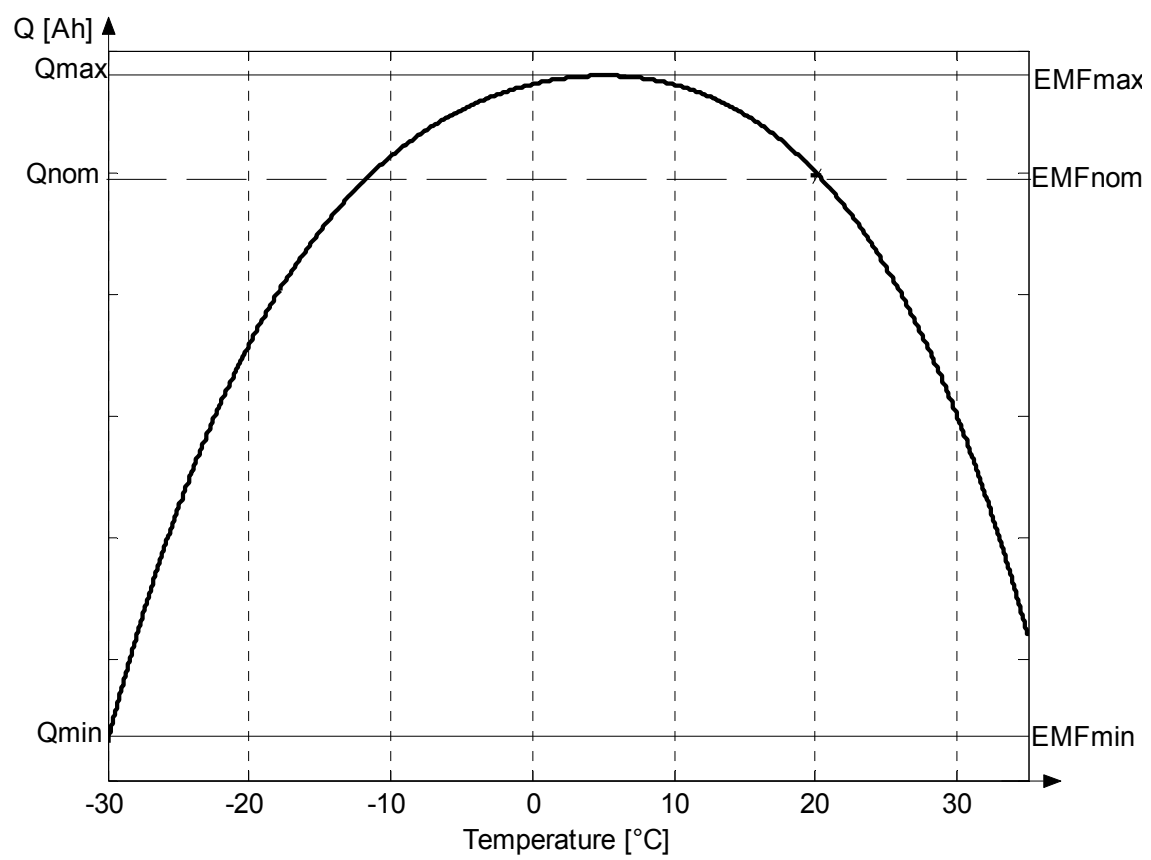

Fig. 18. Temperature dependence of the battery usable discharge capacity and the EMF starting point

From Fig.18, it is easy to note that the EMF (in the case of this battery type) value in the nominal conditions is smaller than the EMF value for a temperature that is lower than $20^{\circ} \mathrm{C}$ (the nominal temperature), which means that for a maximum EMF value, the available battery capacity is higher than in the case of the nominal terms. For nominal conditions, the SOC can be defined by a $\mathrm{k}$ factor $(k \in<1,0>)$. If the EMF for the non-nominal conditions reaches its highest value, the available charge (in ampere-hours) will be also greater. It is easy to note the relation $Q_{\tau}=Q_{\max }$ and $Q_{\text {nom }}$ is defined as follows:

$$
\frac{Q_{\tau}=Q_{\max }}{Q_{\text {nom }}}>1 \text { [If } Q_{\tau}<Q_{\text {nom }} \rightarrow \frac{Q_{\tau}}{Q_{\text {nom }}}<1 \text {, correspondingly, } E M F_{\tau}<E M F_{\text {nom }} \rightarrow \frac{E M F_{\tau}}{E M F_{\max }}<1 \text { ] }
$$

This corresponds to:

$\frac{E M F_{\tau}=E M F_{\max }}{E M F_{\text {nom }}}>1$. On the other hand, for $Q_{\text {nom }}, k \in<1,0>$, but relating it to $Q_{\tau}>Q_{\text {nom }}$ in $\tau$ condition, the file $\langle 1,0\rangle$ means file $\left.<0, Q_{\max }\right\rangle$. Transforming $\mathrm{k}$ in nominal terms to $\mathrm{k}_{\mathrm{\tau}}$ is necessary to use the general relation $\frac{Q_{\tau}}{Q_{\text {nom }}}$. Theoretically, the product $k_{\text {nom }} \frac{Q_{\tau}}{Q_{n o m}}$ transfers the SOC factor into other than nominal temperature conditions. The same transformation can be obtained for $k_{\text {nom }} \frac{E M F_{\tau}}{E M F_{\text {nоm }}}$, where $k_{\text {nоm }} \in<1,0>$. 


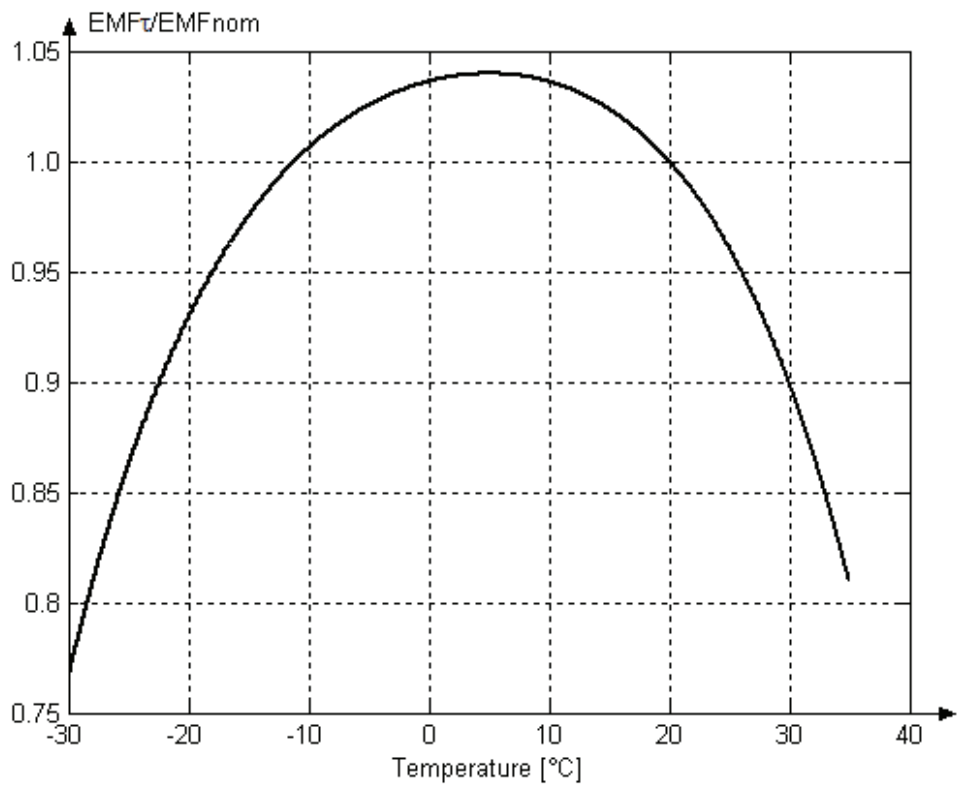

Fig. 19. Relation of $\frac{E M F_{\tau}}{E M F_{\text {nom }}}$ and temperature

Using the transformation factor $k_{\text {nom }} \frac{E M F_{\tau}}{E M F_{\text {nom }}}$ or $k * s_{\tau}\left(k_{\text {nom }}=k, s_{\tau}=\frac{E M F_{\tau}}{E M F_{\text {nom }}}\right)$,it is possible to relate the SOC of the battery that is determined for the nominal temperature to other different temperatures.

\section{Algorithm of battery SOC indication}

The algorithm is given as follows.

1. By simulation, the family of $u_{b}(k)$ for different constant currents $i_{b} \in<0.5 C, 6 C>$ and nominal temperature (e.g. $20^{\circ} \mathrm{C}$ ) can be obtained according to battery modeling results (EMF and internal resistance as functions of SOC).

2. From Fig.19, $s_{\tau}=\frac{E M F_{\tau}}{E M F_{\text {nom }}}$ is defined for $\tau \in<-30^{\circ} \mathrm{C},+35^{\circ} \mathrm{C}>$

3. From Fig.20, for $\mathrm{k}=0.9, \ldots 0.2$, the following lookup table can be obtained

$$
k=0.9 \Rightarrow\left[\begin{array}{l}
u_{11}, i_{11}, E_{1} \\
u_{12}, i_{12}, E_{1} \\
\ldots \\
u_{1 n}, i_{1 n}, E_{1}
\end{array}\right] \cdots . k=0.2 \Rightarrow\left[\begin{array}{l}
u_{81}, i_{81}, E_{8} \\
u_{82}, i_{82}, E_{8} \\
\ldots \\
u_{8 n}, i_{8 n}, E_{8}
\end{array}\right]
$$

Because of the practical limitation of the SOC alteration of the battery that is applied in hybrid drives, the range of $\mathrm{k}$ changes can be expressed as $\langle 0.9,0.2\rangle$ for the nominal temperature. 


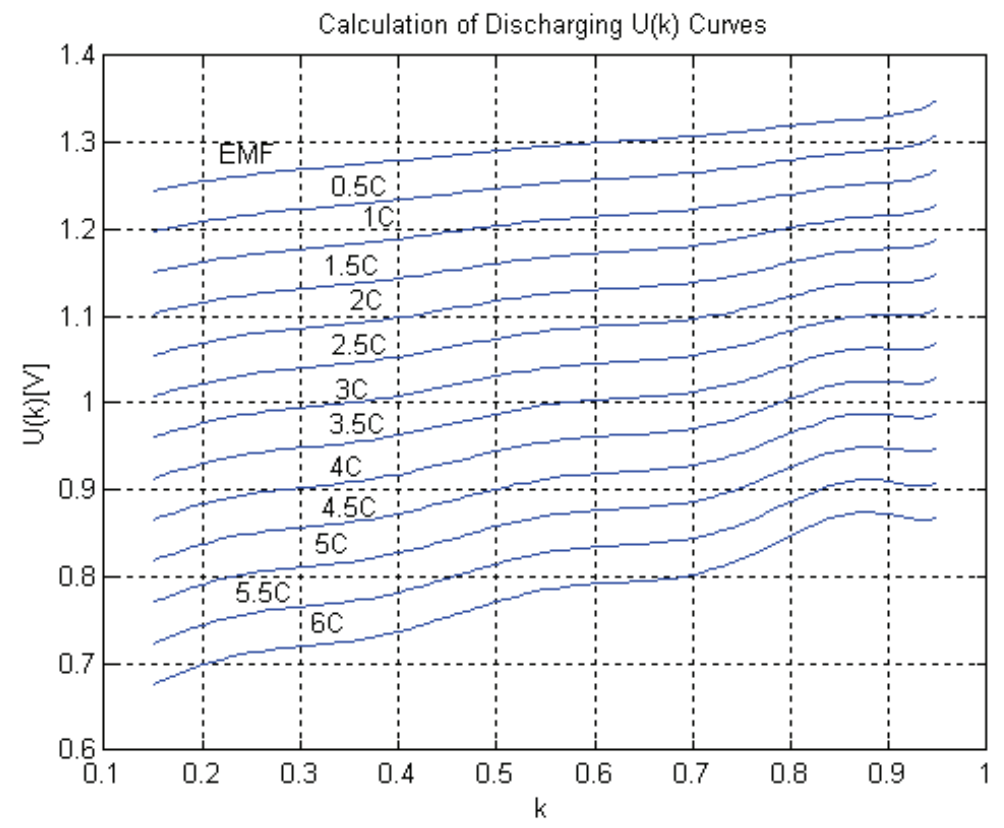

Fig. 20. EMF and calculated discharging voltage characteristics at different discharging current and nominal temperature

4. Considering the real temperatures, the SOC of the battery in relation to the nominal temperature can be defined as $s_{\tau} * k=k_{\tau}$ For instance, at a temperature of $+5^{\circ} \mathrm{C}$, $\frac{E M F_{\tau}}{E M F_{\text {nom }}}=1.06$; hence, $k_{+5^{\circ} \mathrm{C}}=1.06 k$, which means that at this moment and this temperature, the available capacity is 1.06 times that of the nominal temperature. At a temperature $+30^{\circ} \mathrm{C}, \frac{E M F_{\tau}}{E M F_{n o m}}=0.89$; hence, $k_{+30^{\circ} \mathrm{C}}=0.89 k$, which means that at this moment and this temperature, the available capacity is 0.89 times that of the nominal temperature.

A similar method and process can be used for the battery charging process (see Fig.21) The above-depicted method can be used in design of battery management system ( BMS ) for the SOC determination and indication, especially in hybrid ( HEV ) and electric ( EV ) vehicle drives. Based on the aforementioned steps 1) - 4), the SOC indication algorithm can be depicted as is shown in Fig.22.

In HEV the battery SOC changes faster ( because HP high power battery is used ) but not so deep as in pure electric vehicles, equipped with high energy ( HE ) battery. It means that the SOC indication - display process may not be realized as frequently. It's not necessary to display the SOC of the battery every second. Certainly, the previous value of the SOC has to be remembered by a microprocessor.

High accuracy of determination of battery SOC is at first of all necessary for entire drive system control. In opposed to indication - display, the feedback SOC signals from battery must be available online. 


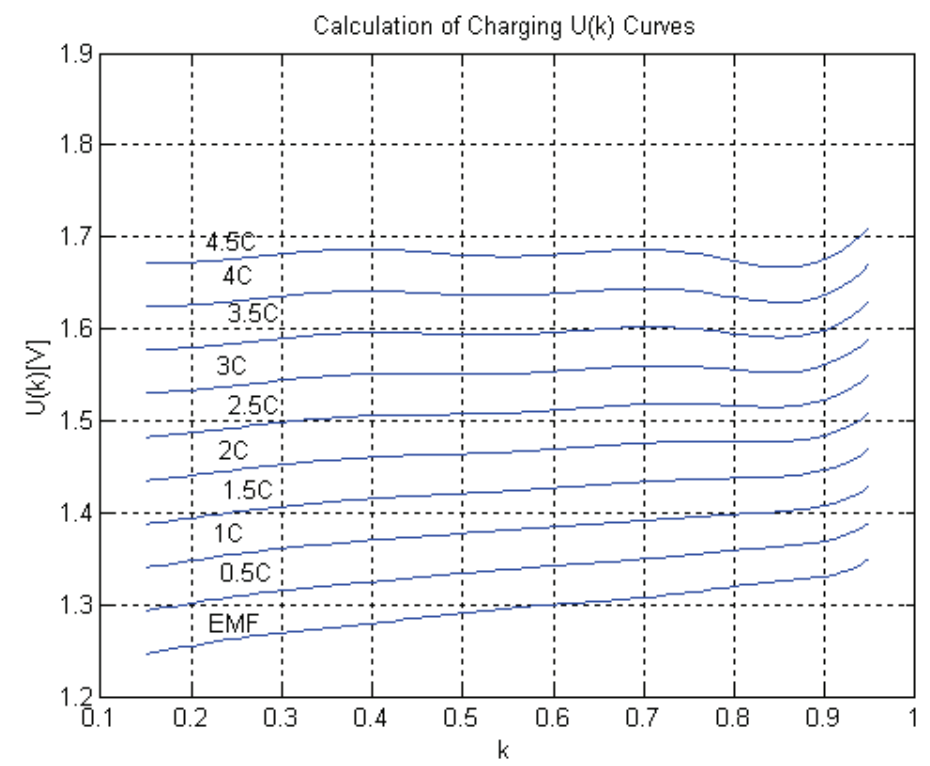

Fig. 21. EMF and calculated charging voltage characteristics at different charging current and nominal temperature

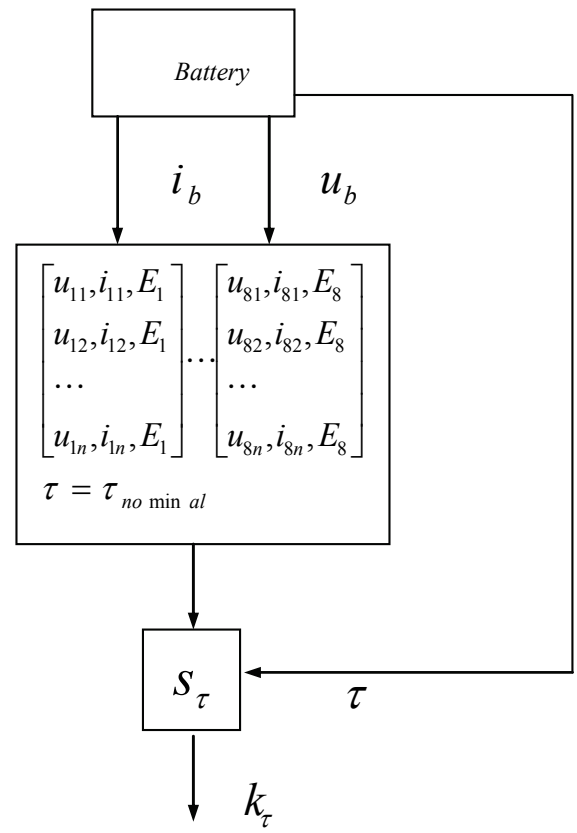

a) Discharging

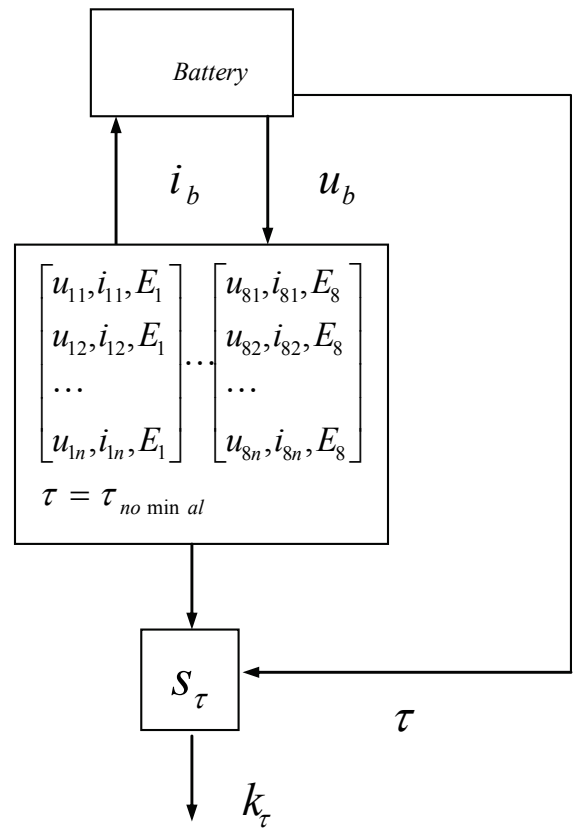

b) Charging

Fig. 22. SOC indication algorithm 
The presented original method of EMF ( as function of $\mathrm{k}$ - SOC ) calculation is the background for constructing BMS. This procedure is easily adopted for control application in HEV and EV. Its high accuracy is very important for control drive systems ( master controller ) based on feedback signals from BMS.

The following equation is the background to determine accurate value of $\mathrm{SOC}(\mathrm{k})$ for dynamic conditions.

$$
\begin{aligned}
& u(t)=E(k) \pm R_{w}(k) i(t) \\
& k=k_{\text {nom }} s_{\tau}
\end{aligned}
$$

+ is for discharge; - is for charge; where $E(k)$ and $R_{w}(k)$ are taken from equation (17) for real battery module.

Based on equation (18), the SOC calculation can be obtained in a direct way in "online" dynamic battery voltage and current alterations. The solving (17) as high power factor polynomial is really possible "online" by using two procedures: look-up table (dividing polynomial function in shaped-line ranges) or "bisection" numerical iterative computation. In some cases, when the accuracy of SOC indication can be lower (about 5\%), which is accepted in HEV and EV drives, power factor of polynomial can be decreased by additional approximation $\mathrm{E}(\mathrm{k})$ and $\mathrm{R}_{\mathrm{w}}(\mathrm{k})$. The accuracy of real time calculation is about $100 \mu$ s.

The second method is "bisection" iterative calculation.

The exemplary plots of battery voltage, current and SOC is shown in following figures 23, 24,25 . Because The SOC of battery is much slower changeable than its voltage and current, the SOC indication is computed and indicated by using "moving average" procedure.

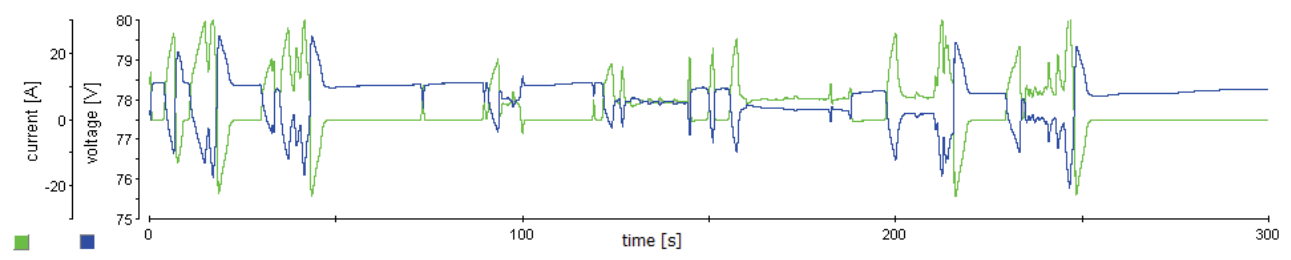

Fig. 23. Exemplary test of battery load in hybrid drive ; blue- battery current, green- battery voltage

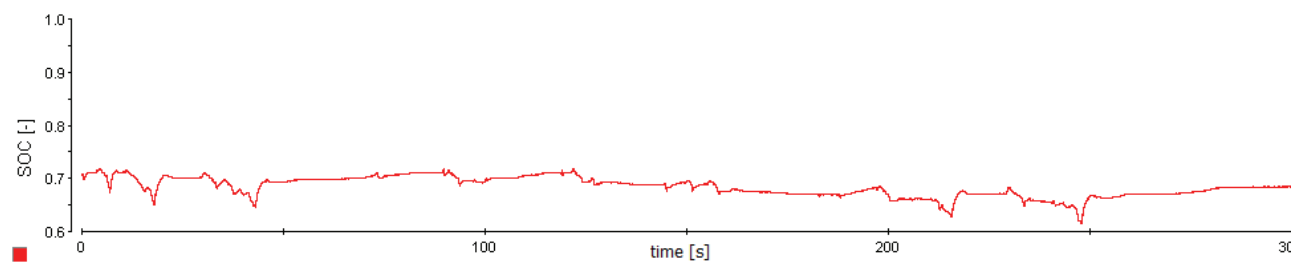

Fig. 24. Exemplary test of battery SOC indication in real drive conditions corresponding to battery load shown in Fig.23. 


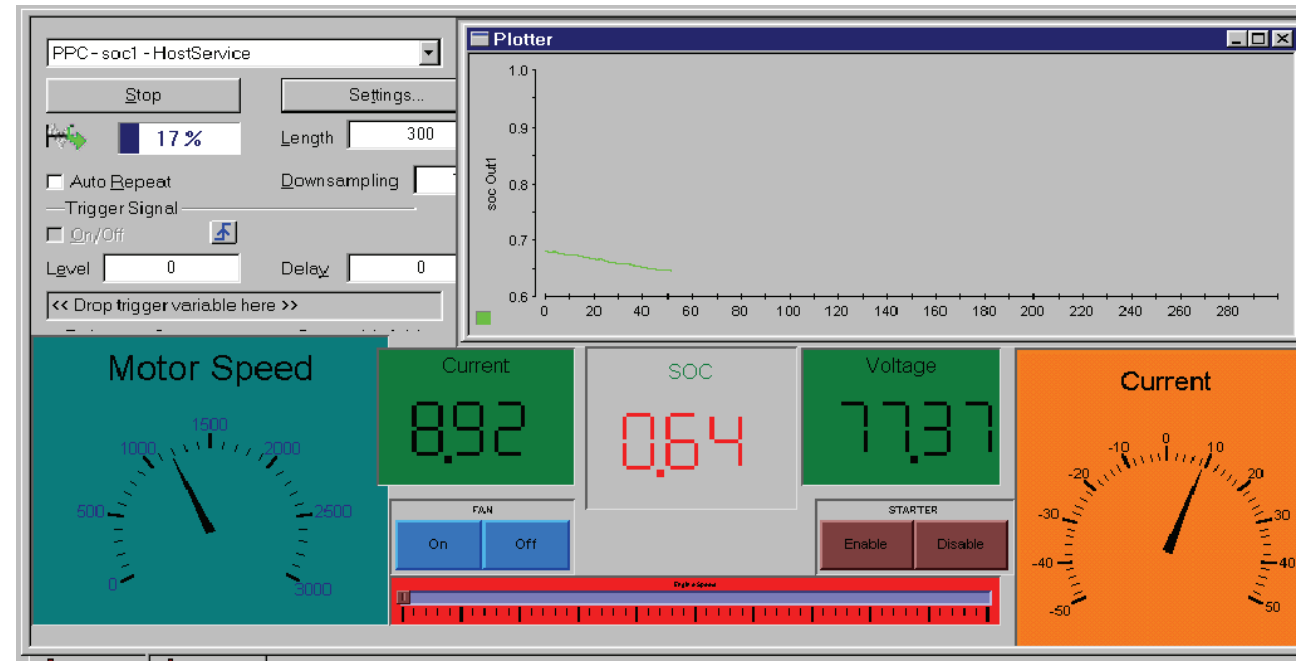

Fig. 25. Screen of control system based on d'Space programming for SOC indication.

\section{Conclusions}

The assumed method and effective model are very accurate according to error checking results of the NiMH and Li-Ion batteries. The modeling method is valid for different types of batteries. The model can be conveniently used for vehicle simulation because the battery model is accurately approximated by mathematical equations. The model provides the methodology for designing a battery management system and calculating the SOC. The influence of temperature on battery performance is analyzed according to laboratory-tested data and the theoretical background for the SOC calculation is obtained. The algorithm of the battery SOC "online" indication considering the influence of temperature can be easily used in practice by a microprocessor

\section{References}

[1] K. L. Butler, M. Ehsani, and P. Kamath, "A matlab-based modeling and simulation package for electric and hybrid electric vehicle design," IEEE Trans. Veh. Technol., vol. 48, no. 6, pp. 1770-1778, Nov. 1999.

[2] O. Caumont, P. L. Moigne, C. Rombaut, X. Muneret, and P. Lenain,“Energy gauge for lead acid batteries in electric vehicles," IEEE Trans. Energy Convers., vol. 15, no. 3, pp. 354-360, 2000.

[3] M. Ceraol and G. Pede, "Techniques for estimating the residual range of an electric vehicle," IEEE Trans. Veh. Technol., vol. 50, no. 1, pp. 109-115,Jan. 2001.

[4] C. C. Chan, "The state of the art of electric and hybrid vehicles," Proc.IEEE, vol. 90, no. 2, pp. 247-275, 2002.

[5] Valerie H. Johnson, Ahmad A. Pesaran, “Temperature-dependent battery models for high-power lithium-ion batteries", in Proc. International Electric Vehicle Symposium, vol. 2, 2000, pp. 1-6. 
[6] W. Gu and C. Wang, "Thermal-electrochemical modeling of battery systems", Journal of the Electrochemical Society vol.147, No.8, (2000), pp. 2910-22.

[7] Szumanowski A. "Fundamentals of hybrid vehicle drives" Monograph Book, ISBN 837204-114-8, Warsaw-Radom 2000.

[8] Szumanowski A. "Hybrid electric vehicle drives design-edition based on urban buses" Monograph Book, ISBN 83-7204-456-2, Warsaw-Radom 2006.

[9] Robert F. Nelson, "Power requirements for battery in HEVs", Journal of Power Sources,vol. 91, pp.2-26, 2000.

[10] E. Karden, S. Buller, and R. W. De Doncker, "A frequency-domain approach to dynamical modeling of electrochemical power sources," Electrochimica Acta, vol. 47, no. 13-14, pp. 2347-2356, 2002.D.

[11] J. Marcos, A. Lago, C. M. Penalver, J. Doval, A. Nogueira, C. Castro, and J. Chamadoira, "An approach to real behaviour modeling for traction lead-acid batteries," in Proc. Power Electronics Specialists Conference, vol. 2, 2001, pp. 620-624.

[12] A. Salkind, T. Atwater, P. Singh, S. Nelatury, S. Damodar, C. Fennie, and D. Reisner, "Dynamic characterization of small lead-acid cells," J. Power Sources, vol. 96, no. 1, pp. 151-159, 2001.

[13] G. Plett "LiPB dynamic cell models for Kalman-Filter SOC estimation", Proc. International Electric Vehicle Symposium, 2003, CD-ROM.

[14] S. Pang, J. Farrell, J. Du, and M. Barth, "Battery state-of-charge estimation," in Proc. American Control Conference, vol. 2, 2001, pp. 1644-1649.

[15] S. Malkhandi, S. K. Sinha, and K. Muthukumar, "Estimation of state of charge of lead acid battery using radial basis function," in Proc. Industrial Electronics Conference, vol. 1, 2001, pp. 131-136.

[16] S. Rodrigues, N. Munichandraiah, A. Shukla, "A review of state-of-charge indication of batteries by means of a.c. impedance measurements", Journal of Power Sources, vol.87, No.1-2, 2000, pp.12-20.

[17] L. Jyunichi and T. Hiroya, "Battery state-of-charge indicator for electric vehicle," in Proc. International Electric Vehicle Symposium, vol. 2, 1996, pp. 229-234.

[18] S. Sato and A. Kawamura, "A new estimation method of state of charge using terminal voltage and internal resistance for lead acid battery," in Proc. Power, vol. 2, 2002, pp. 565-570.

[19] W. X. Shen, C. C. Chan, E. W. C. Lo, and K. T. Chau, "Estimation of battery available capacity under variable discharge currents," J. Power Sources, vol. 103, no. 2, pp. 180-187, 2002.

[20] W. X. Shen, K. T. Chau, C. C. Chan, Edward W. C. Lo, "Neural network-based residual capacity indicator for Nickel-Metal Hydride batteries in electric vehicles" IEEE Trans. Veh. Technol.,vol. 54, no. 5, pp. 1705-1712, Sep. 2005

[21] K. Morio, H. Kazuhiro, and P. Anil, "Battery SOC and distance to empty meter of the honda EV plus," in Proc. International Electric Vehicle Symposium, 1997, pp. 1-10.

[22] O. Caumont, P. L. Moigne, C. Rombaut, X. Muneret, and P. Lenain,“Energy gauge for lead-acid batteries in electric vehicles," IEEE Trans.Energy Convers., vol. 15, no. 3, pp. 354-360, Sep. 2000. 
[23] Sabine Piller, Marion Perrin, Andreas Jossen "Methods for state-of-charge determination and their applications", Journal of Power Sources, vol. 96 , pp.113-120, 2001 .

[24] Antoni Szumanowski, Jakub Dębicki, Arkadiusz Hajduga, Piotr Piórkowski, Chang Yuhua, "Li-ion battery modeling and monitoring approach for hybrid electric vehicle applications", Proc. International Electric Vehicle Symposium, 2003, CD-ROM.

[25] Antoni Szumanowski, Yuhua Chang "Battery Management System Based on Battery Nonlinear Dynamics Modeling" IEEE Transactions on Vehicular Technology, Vol. 57 no.3 May 2008 


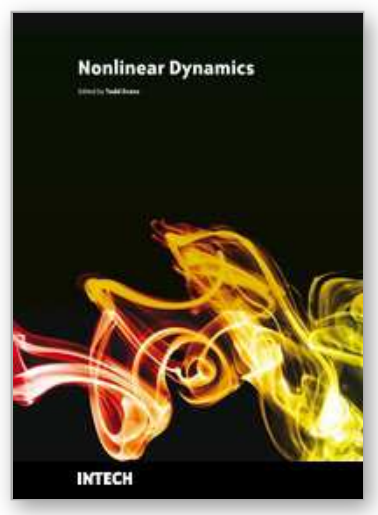

\author{
Nonlinear Dynamics \\ Edited by Todd Evans
}

ISBN 978-953-7619-61-9

Hard cover, 366 pages

Publisher InTech

Published online 01, January, 2010

Published in print edition January, 2010

This volume covers a diverse collection of topics dealing with some of the fundamental concepts and applications embodied in the study of nonlinear dynamics. Each of the 15 chapters contained in this compendium generally fit into one of five topical areas: physics applications, nonlinear oscillators, electrical and mechanical systems, biological and behavioral applications or random processes. The authors of these chapters have contributed a stimulating cross section of new results, which provide a fertile spectrum of ideas that will inspire both seasoned researches and students.

\title{
How to reference
}

In order to correctly reference this scholarly work, feel free to copy and paste the following:

Antoni Szumanowski (2010). Nonlinear Dynamics Traction Battery Modeling, Nonlinear Dynamics, Todd Evans (Ed.), ISBN: 978-953-7619-61-9, InTech, Available from: http://www.intechopen.com/books/nonlineardynamics/nonlinear-dynamics-traction-battery-modeling

\section{INTECH}

open science | open minds

\section{InTech Europe}

University Campus STeP Ri

Slavka Krautzeka 83/A

51000 Rijeka, Croatia

Phone: +385 (51) 770447

Fax: +385 (51) 686166

www.intechopen.com

\section{InTech China}

Unit 405, Office Block, Hotel Equatorial Shanghai

No.65, Yan An Road (West), Shanghai, 200040, China

中国上海市延安西路65号上海国际贵都大饭店办公楼 405 单元

Phone: +86-21-62489820

Fax: $+86-21-62489821$ 
(C) 2010 The Author(s). Licensee IntechOpen. This chapter is distributed under the terms of the Creative Commons Attribution-NonCommercialShareAlike-3.0 License, which permits use, distribution and reproduction for non-commercial purposes, provided the original is properly cited and derivative works building on this content are distributed under the same license. 